mucosa; (4) parasitic; (5) endothelial ; (6) dermoid; and (7) papilliferous.' Howard Kelly looks to the scarred tissue of some traumatism; to Gärtner's ducts, and, following Rouget, to glandular degeneration for their origin. I am not here considering cysts arising from Skene's glands and urethral cysts. As to the size of these cysts, all authorities are agreed that it is very rare for them to reach the size of a hen's egg; it is more common to find them about that of a bazel nut or a cherry. They may be discovered in any part of the vaginal canal, in the vault, near the portio, in its wall, or in the vulva, more frequently anteriorly or laterally.

Before detailing the particulars of my case I may refer to that of Dr. Santi. In a patient who was suffering from cystocele three small cysts of the size of cherries were found. All three were on the same level and one inch distant from the urethra. These, with the adjacent tissue, were excised. It was then seen that they were connected together by a cord-like growth. Suffice it here to say that careful microscopical examination proved these cysts to be lined with cubical epithelium, the partition between them consisting of muscular tissue, alkaline matter, and connective tissue. The duct-like nature of the connecting links between these cysticles was proved, the lumen dilating at intervals to form the cystic cavities and preserving a close similarity in structure to these. From the position of these cysts and from embryological and histological grounds Dr. Santi concludes that there cannot be any doubt as to their Wolffian origin. This proof appears to be the most absolute of any hitherto published of their origin. The epithelial lining affords the best clue to the origin of these cysts. As will be seen in one of the cysts removed by me the lining epithelium was the same as that found in Dr. Santi's case-namely, cubical. Kelly says that in the cysts of glandular origin the epithelium is columnar but that when they arise from scar tissue it is squamous. Freund's description of Müllerian cysts is quoted by Williams as follows: "They are present in the portio and upper part of the vagina. They are thick-walled, with well-developed musculosa. Columnar epithelium lines the interior, sometimes ciliated. It may be involuted and cryptic. The contents are viscid and like white of egg."

My patient was a married woman, aged 35 years. She had had no children. She consulted me for endometritis, for which she was curetted in September, 1905. The variety proved to be glandular endometritis. In carrying out the curettage $I$ discovered in the vaginal vault a cystic tumour fully of the size of a large pigeon's egg. This I dissected completely out but the glairy fluid escaped and I could not remove it in its entirety. Only part of the cyst could therefore be sent for examination. Dr. Cuthbert Lockyer reported that this was lined by epithelium of the spherical type. $\mathrm{He}$ thought that it might be a distension cyst found in some

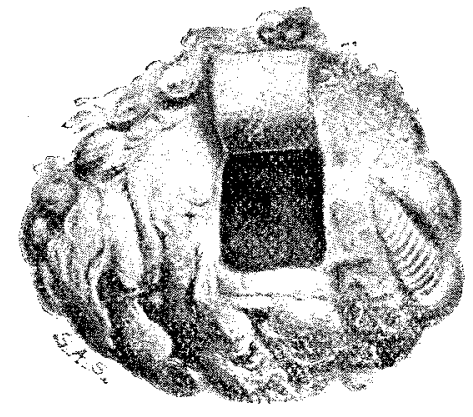

pre-existing space. In December, 1905, the patient came again, complaining of vaginal distress and pain. On examination I was surprised to find low down on the posterior wall of the vagina, and inclining to the right side, a fair-sized cyst distended with fluid and nearly of the size of the one removed in September. This had evidently been concealed by the large blade of the retracting speculum at the time of operation. I determined to dissect the cyst out in its entirety so as to preserve it for careful examication. This $I$ had some difficulty in doing, as its wall was thin and incorporated with the subjacent tissue in the recto-vaginal septum, and closely applied to the rectum.

1 Vaginal Tumours with Special Reference to Cancer and Myoma,
Through a small cut some of the thin clear fluid it contained escaped. The cyst, reduced in size from contraction through its preservation, is shown in the illustration. Dr. Lockyer reported it as "circular in shape, an inch in diameter, with a surrounding of fibro-muscular tissue. It has a convoluted waxy lining and in the depth between the folds the microscope shows the presence of cubical epithelium."

I am not aware of any cases having been published in which two cysts of the size $I$ have mentioned, and obviously of different characters and origin, occurred in different portions of the vagina. It would seem to me as if the one which was in the vaginal vault had a glandular origin, whereas the one in the lower portion of the canal was of a Gärtnerian or Wolffian nature.

Harley-street, W.

\section{AN ATTEMPT TO SIMPLIFY THE DIAGNOSIS OF OCULAR PARALYSIS.}

By WALTER H. HAW, B.A., M.R.C.S. EnG., L.S.A.

I HAVE been much interested in the two articles on the diagnosis of ocular paralysis which have lately appeared in THE LANCET ${ }^{1}$ and have been gratified to find that general practitioners are not alone in their troubles in this matter. As a matter of fact, as taught in the text-books, this subject has become a mere effort of memory except in the case of those who have worked out the why and wherefore. I have usually found that it is easier to forget a mnemonic than the establisbed facts of anatomy and physiology learnt in student days. If the mind can easily follow out the processes by which results are reached there will be no need of mnemonics. My aim in this communication is to try to explain the results of ocular paralysis in such a way that the diagnosis of the paralysed muscle is a perfectly simple matter and can be thought out straightforwardly and rapidly-at any rate theoretically,

Underlying the method are the following three statements learnt in student life: $\boldsymbol{A}$. A paralysed ocular muscle cannot moved the eyeball in the direction of its action. $B$. When diplopia occurs as a result of paralysis the false image of a candle held in the field of action of the paralysed muscle is displaced in the direction of the action of that muscle. $C$. Paralysis of an inward-acting muscle produces crossed diplopia; paralysis of an outward-acting muscle produces uncrossed diplopia. Inward-acting muscles
Outward-acting muscles $\ldots\left\{\begin{array}{c}\text { Superior, internal, inferior rectus. } \\ \text { Superior oblique, external rectus, } \\ \text { inferior oblique. }\end{array}\right.$

I am sure it will be easier to remember the above three statements than any arbitrary mnemonic. Let me now apply them in the case of paralysis of the external rectus, the easiest to follow.

External rectus.-Action: moves the eyeball horizontally outwards. With paralysis the corresponding eyeball cannot move horizontally outwards consensually with its fellow which moves horizontally inwards. Hence, the image of a candle held in the field of action of the paralysed external rectus will fall, in the sound eye, on the yellow spot; in the unsound eye on the retina some distance from the yellow ; pot on the nasal side. The false image is projected towards the temporal side-i.e., in the direction of action of the external rectus muscle. Being an outward-acting muscle, the diplopia is uncrossed. In order to find out the effect of paralysis of the external rectus muscle we ask ourselves, What is its action? And the answer, helped out by the three foregoing statements, gives the effect of the paralysis. Thus the external rectus is an outward-acting muscle, therefore the diplopia is uncrossed; it moves the eyeball horizontally outwards, therefore the false image, in paralysis of it, is displaced horizontally outwards. So with all the other muscles.

It is necessary also to remember another physiological fact, which may be added to the others, making four short statements to be committed to memory. $D$. The consensually acting muscles are as follows: External and opposite 
internal rectus (eyes turned right or left); superior rectus and opposite inferior oblique (eyes turned upwards and towards the side of the oblique muscle); inferior rectus and opposite superior oblique (eyes turned downwards and towards the side of the oblique muscle). Omitting the external rectus, let me go through the actions of the muscles in order.

Aation of the internal reotus.-Consensual with the opposite external rectus ; inward acting (diplopia crossed). The eyeball is moved horizontally inwards (false image displaced horizontally inwards). (See Fig. 1.)

$$
\text { FIG. 1. }
$$

Superior reotus.-Consensual with the opposite inferior oblique ; inward acting (diplopia crossed). The eseball is moved upwards and inwards with a wheel motion inwards (the eyeball tends to roll towards the nose). The upward movement is most marked in the position of abduction and the wheel motion is most marked in the position of adduc. tion, as is evident on consideration of the anatomical relations of the eyeball to its muscles. The false image is correspondingly displaced (see Fig. 2).

FIG. 2.

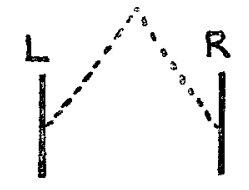

Inferior rectus.-Consensual with the opposite superior oblique ; inward acting (diplopia crossed). The eyeball is moved downwards and inwards with a wheel motion outwards (the eyeball tends to roll towards the temporal region). The false image is correspondingly displaced. The downward action is greatest in the position of abduction, the wheel motion in the position of adduction (see Fig. 3).

FIG. 3.<smiles>[R]C(C)[CH][CH][V]</smiles>

Inferior oblique.-Consensual with the opposite superior rectus ; outward acting (diplopia uncrossed). The eyeball is moved upwards and outwards with a wheel motion outwards (the eyeball rolls towards the temporal region). The false image is correspondingly diplaced (see Fig. 4).

FIG. 4.

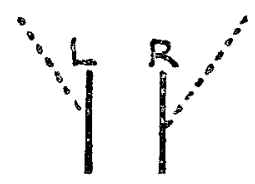

Superiar oblique.-Consensual with the opposite inferior rectus; outward acting (diplopia uncrossed). The eyeball is moved downwards and outwards with a wheel motion inwards. The false image is correspondingly displaced (see Fig. 5).

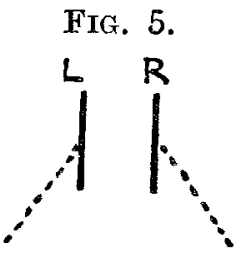

To examine one or two supposed cases, place a red glass in front of the right eye. Hold a candle in the mid-line in the upper field. Suppose we get a red image on the right side which follows the movement of the candle (uncrossed diplopia, therefore an outward-acting muscle). Suppose, further, it is higher than the other; this points to an elevator. Therefore we have an outward-acting elevator of the right eye involved. This can only be the right inferior oblique.

Hold a candle in the lower field - that is, in the field of action of the inferior rectus and opposite superior oblique. If we get a red image on the left and below, which sinks on lowering the candle, we know it is the right eye which is affected. The diplopia being crossed tells us it is an inwardacting muscle of the right eje. The displacement downwards proves that it is a depressor. Therefore it is the inferior rectus.

It is now possible to follow mentally with ease $\mathrm{Mr}$. E. E. Maddox's mnemonic as given by Dr. A. S. Percival. The wheel motions and the crossed or uncrossed nature of the diplopia being neglected, the relative height alone of the images is considered, in the right and left upper, and the right and left lower, fields.

The whole of the foregoing is ancient history but I have thought that in this form it may be of use. By making the two hands take the place of the two images it is possible to run rapidly through their various relations in the different forms of paralysis with very little mental effort. We can also easily follow Dr. D. M. Mackay's article without the aid of a diagram. In the example which he takes-viz., paralysis of an elevator of the right eye-let us proceed according to the foregoing method. With a red glass before the right eye, it is found that the red image is on the left of the yellow and higher and rises on lifting the candle. 'This shows crossed diplopia (inward-acting muscle) and paralysis of an elevator of the right eye-viz., the superior rectus ; and as the elevating action increases in the abducted position, the false image will rise on moving the candle outwards (to the right). In the case of paralysis of the inferior oblique of the right eye it is an outward-acting muscle (uncrossed diplopia), so that the red image would be on the right of the yellow and higher, and on moving the candle to the left the false image would rise higher, for the right eye would become adducted, in which position elevation is most marked.

Knysna, Cape Colony.

Erratum.-Sir William H. Bennett points out that the diagram in his lecture upon Appendicostomy, which appeared in THE LANCET of Feb. 17th, was reversed in the printing.

\section{Clinitad a dotes: MEDICAL, SURGICAL, OBSTETRICAL, AND THERAPEUTICAL.}

\section{A NOTE OF A OASE OF CONFLUENT VARIOELLA.}

BY J. T. NeECH, M.D. DuRH., D.P.H., MEDICAL OFFICER OF HEALIH OF HALIFAX.

THE patient, a female, aged four years, was admitted into the Halifax borough fever hospital suffering from a mild attack of scarlet fever. She made favourable progress until the evening of Jan. 3rd, 1906, when without any premonitory symptoms the temperature suddenly went up to $102^{\circ} \mathrm{F}$. One or two papules on the face and body were then present and on the following morning a profuse crop of both papules and vesicles appeared all over the body and legs. The skin generally was very much congested where the rash appeared. The papules which had appeared on the previous day had now become pustular. The temperature remained near $102^{\circ}$ during the 4th but on the morning of the 5 th it fell to normal. In the meantime the vesicles increased in number and size and became confluent on the body and especially on the thighs, many of them being umbilicated. On the evening of the 6 th the temperature again went up to $101.4^{\circ}$, which was followed by a further crop of papules and vesicles on the face, head, and arms almost as profuse as the former crop on the body. A number of the vesicles on the body and legs had now become pustular. On the evening of the 7th the temperature had fallen to $99^{\circ}$. It rose again to $100.4^{\circ}$ on the 8th and fell to normal on the 9 th and afterwards remained there. There was cedema of the face, a great many 